\title{
Isolation and Identification of Biofilm-Forming Staphylococcus Aureus in Commercial Cow Milk Products
}

\author{
Dominggas Yembise ${ }^{1}$, Catarina Aprilia Ariestanti ${ }^{1}$, and Tri Yahya Budiarso ${ }^{1 *}$ \\ ${ }^{1}$ Faculty of Biotechnology, Duta Wacana Christian University, Yogyakarta, Indonesia
}

\begin{abstract}
Food poisoning caused by the contamination from Staphylococcus aureus are frequently found in food especially in dairy products. Pasteurization process in milk production was not enough to kill S. aureus because it formed biofilm that could survive in high temperature. This research aimed to study the presence of biofilmforming S. aureus in samples from packed commercial milk products in Yogyakarta City, Indonesia. Twenty isolates from dairy products were grown in Brain Heart Infusion (BHI) broth then inoculated into Braid-Parker Agar (BPA) medium to get the candidate of $S$. aureus isolates. These isolate candidates were selected using Mannitol Salt Agar (MSA) and Congo Red Agar (CRA) medium. Another selection was done by carbohydrate fermentation analysis and confirmed using API STAPH. Confirmation analysis showed that eight isolates were identified as S. aureus. Another two isolates were identified as S. xylosus and S. haemolyticus. Therefore, it indicated the presence of Staphylococcus aureus as contaminant in dairy products.
\end{abstract}

Keywords: Staphylococcus aureus, packed milk product, biofilm, API STAPH

\section{Introduction}

Staphylococcus aureus is pathogenic bacteria that easily transferred through food and caused foodborne illness. This phenomenon is globally important. S. aureus affected the human and animal health. It infected human through the consumption of contaminated food. In China, $53.7 \%$ of food poisoning cases were caused by $S$. aureus in 2015 (Wu et al., 2018). The highest cases of foodborne diseases in United States were reported caused by S. aureus with 241,000 cases per year (Kadariya et al., 2014). Dairy milk product was one of the main sources of food poisoning caused by Staphyloccus. The bacteria could survive during the pasteurization process and produced enterotoxin that can be involved in the product (Johler et al., 2015; Jin and Yamada, 2016). Isolates of S. aureus from pasteurized milk products in China were reported to have the ability to produce biofilm $(96.7 \%)$ and $66.7 \%$ isolates had the virulence factor to cause diseases (Dai, 2019). Castelni (2014) reported that $S$. aureus produced

\footnotetext{
*Corresponding author:

Tri Yahya Budiarso

Faculty of Biotechnology, Duta Wacana Christian University. Jl. Dr. Wahidin, S. No 5-25 Yogyakarta, Indonesia 55224

E-mail: yahya@staff.ukdw.ac.id
}

Staphylococcus enterotoxin (SEs) in food and if it consumed, it can lead to high fever and vomiting with or without diarrhea and nausea in less than $8 \mathrm{~h}$ (between 3 and $4 \mathrm{~h}$ ).

Research conducted by Qian et al. (2019) , showed that from 289 samples collected from food poisoning cases because of goat milk consumption in Shaanxi, China, 68 isolates of S. aureus were found and $91.8 \%$ had a close relation with its ability to produced biofilm with antibiotic-resistance characteristic. Biofilm formation made $S$. aureus has the ability to colonize, resistance to antibiotic with high level of virulent characteristic (Rohinishree, 2011). In Yogyakarta City, packed-pasteurized dairy milk products are one of the favorite drinks for the society, especially students because of its high nutrition content, relative cheap price, simplicity and easiness to be carried everywhere. The aim of this research was to find the presence of biofilm-forming Staphylococcus in packed commercial dairy milk products in Yogyakarta City, Indonesia.

\section{Materials and Methods Materials}

The samples were 20 packs of cow milk products from 5 kinds of milk with different brands that have been randomly collected from shops and supermarkets in Yogyakarta 
City, Indonesia. Brain Heart Infusion (BHI) broth, Baird-Parker Agar (BPA), Mannitol Salt Agar (MSA), Brain Heart Infusion Agar (BHIA), Congo Red Agar (CRA) and peptone water were purchased from Millipore Corp. (Massachusetts, USA). API STAPH was purchased from bioMerieux Company (Marcy-l'Étoile, France). All chemicals and reagents were of analytical grade.

\section{Methods \\ Isolation step}

Each sample $(10 \mathrm{ml})$ was taken and grown in $90 \mathrm{~mL}$ BHI broth media then incubated for 16-18 h (Palilu \& Budiarso, 2017). Incubated sample $(1 \mathrm{ml})$ was then diluted using $0.1 \%$ peptone water $(9 \mathrm{ml})$ into solution with the concentration from $10^{-1}$ to $10^{-6}$ and homogenized using vortex. Diluted sample $(0.1 \mathrm{ml})$ from the concentration of $10^{-4}$, $10^{-5}$ and $10^{-6}$ were inoculated to the surface of BPA medium and spread using drygalsski and incubated for $48 \mathrm{~h}$ at $37^{\circ} \mathrm{C}$. Suspected colonies of Staphylococcus expressed in dark grey to shinning black color in BPA medium (Sutejo et al., 2017). Purification was done for these suspected colonies by taking the separate colonies and inoculating them in BPA medium using streak plate technique to get the single colony. This suspected Stahpyloccous single colony then streaked into MSA medium and incubated for $24 \mathrm{~h}$. Colony that expressed in yellow color was then separated into another BPA medium to get the single isolate. This isolate was finally grown in BHIA medium and collected as $S$. aureus suspected isolate (Olwal et al., 2018).

Selection of Biofilm-forming Staphylococcus Single suspected isolate of $S$. aureus from BHIA medium was inoculated into the surface of CRA medium by streak plate technique then incubated for $24 \mathrm{~h}$ at $37^{\circ} \mathrm{C}$. Staphylococcus aureus that produced slime were expressed in black colony. Congo Red Agar medium contains of BHI broth $(37 \mathrm{~g} / \mathrm{L})$, agar base $(10 \mathrm{~g} / \mathrm{L})$, saccharose $(36 \mathrm{~g} / \mathrm{L})$ and Congo Red dye $(0.8 \mathrm{~g} / \mathrm{L})$ as the biofilmforming indicator (Bnyan, 2017; Casagrande Proietti et al., 2015).

\section{Biochemistry Confirmation Analysis using API STAPH}

According to the reference method from Savage et al. (2017) and Vanderhaeghen et al. (2015), there were three steps in confirmation analysis including preparation the API STAPH stripe, inoculum preparation and inoculation process. Incubation process was done for $18-24 \mathrm{~h}$ in $37^{\circ} \mathrm{C}$ and the observation was conducted for $24 \mathrm{~h}$ by adding NIT 1 and NIT 2 reagents into NIT well, Zym A and Zym $B$ reagents into PAL well and VP1 and VP2 reagents into VP well. Color changing was observed and identified using APIWEB software version 1.3.0 (bioMerieux Company, Marcy-l'Étoile, France).

\section{Result \\ Isolation and Selection of Staphylococcus aureus}

Staphylococcus aureus was isolated from 20 kinds of different cow milk product. Isolation was done by inoculated the culture into BPA medium by adding egg yolk tellurite. The presence indicator of suspected $S$. aureus in the milk product was the black color in the colony with clear zone surrounding it (Figure 1.) The suspected

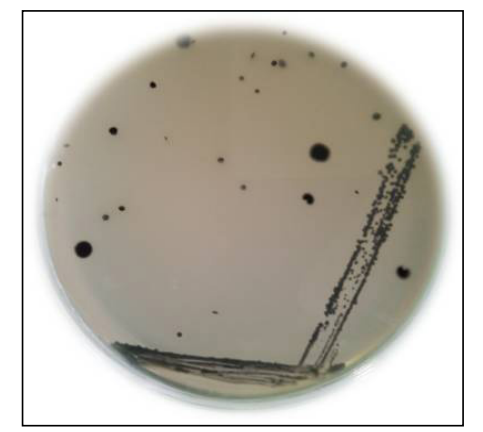

Figure 1. The growth of colony in BPA medium

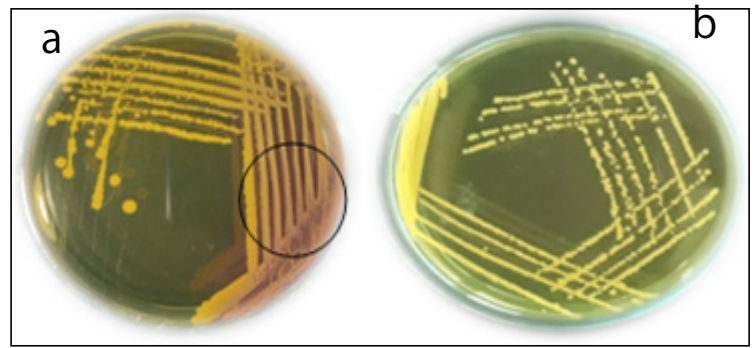

Figure 2. The growth of colony in MSA medium; negative (a) and positive (b) 
Table 1. Carbohydrate fermentation analysis of suspected S. aureus isolates

\begin{tabular}{|c|c|c|c|c|c|c|c|}
\hline Isolate code & Xylose & Maltose & Sucrose & Galactose & Mannitol & VP & Predicted \\
\hline S.U.1.1 & - & + & + & - & + & + & S.aureus \\
\hline S.U.1.2 & + & - & - & + & - & - & S.xylosus \\
\hline S.U.1.3 & - & - & + & - & - & - & ND \\
\hline S.U.3.2 & - & + & + & - & + & + & S.saprophyticus \\
\hline S.U.3.4 & - & + & + & + & + & + & S.aureus \\
\hline S.U.4.1 & - & + & - & + & - & - & S.auricularis \\
\hline S.B.1.3 & - & + & + & - & + & - & S.saprophyticus \\
\hline S.B.3.1 & - & + & + & + & + & + & S.aureus \\
\hline S.B.4.1 & - & + & + & - & - & + & $\begin{array}{l}\text { S.epidremidis/ } \\
\text { S.lugunensis }\end{array}$ \\
\hline S.B. 4.2 & - & + & + & - & - & - & ND \\
\hline S.B.4.3 & + & + & + & + & + & - & S.gallinarum \\
\hline S.P.1.2 & - & + & + & + & - & - & $\begin{array}{l}\text { S.gallinarum/ } \\
\text { S.auricularis }\end{array}$ \\
\hline S.P.1.4 & - & + & + & - & + & - & S.gallinarum \\
\hline S.P.2.1 & - & + & + & + & + & + & S.aureus \\
\hline S.P.4.1 & - & + & + & - & + & + & S.aureus \\
\hline S.K.1.1 & - & + & + & + & + & + & S.aureus \\
\hline S.K.1.2 & - & + & + & + & - & + & S.epidermidis \\
\hline S.M.1.2 & - & - & - & - & - & - & ND \\
\hline S.M.2.3 & - & - & - & - & - & - & ND \\
\hline S.M.4.2 & - & - & - & - & - & - & ND \\
\hline
\end{tabular}

ND: not detected

Table 2. APISTAPH confirmation analysis of suspected S. aureus isolates

\begin{tabular}{llc}
\hline Isolate code & API STAPH confirmation & \multicolumn{1}{c}{ ID $\%$} \\
\hline S.U.1.1 & S. haemolyticus & $85.0 \%$ \\
S.U.1.2 & S. aureus & $87.5 \%$ \\
S.U.3.4 & S. xylosus & $98.7 \%$ \\
S.B.1.3 & S. aureus & $84.3 \%$ \\
S.B.3.1 & S. aureus & $70.0 \%$ \\
S.P.1.4 & S. aureus & $83.3 \%$ \\
S.P.2.1 & S. aureus & $88.7 \%$ \\
S.P.4.1 & S. aureus & $84.0 \%$ \\
S.K.1.1 & S. aureus & $92.5 \%$ \\
S.K.1.2 & S. aureus & $89.0 \%$ \\
\hline
\end{tabular}

colony then selected in MSA medium. The red colony (Fig. 2a; in the circle) growth in MSA medium showed that there was no $S$. aureus detected (negative) while the yellow colony (Fig. 2b) indicated the presence of $S$. aureus (positive) after incubated for $24 \mathrm{~h}$.

\section{Selection of suspected Staphylococcus aureus isolate}

The positive biofilm-forming of suspected $S$. aureus from CRA medium then selected by fermentation analysis using different kind of carbohydrate sources before confirmation analysis using API STAPH. Carbohydrate fermentation analysis (Table 1.) was done to test the bacteria ability to ferment different kinds of sugar.

Isolates with predicted $S$. aureus Table 1. then analyzed for confirmation analysis using API STAPH. Isolates with different predicted species of Staphylococcus were taken (one isolate per species) for confirmation analysis and the results shows in Table 2 . The medium in this analysis consisted of 20 sugar mediums to test the homogeneous suspension of bacteria using McFarland 0.5 standard to see its level of turbidity. Medium containing bacterial suspension was then incubated at $37^{\circ} \mathrm{C}$ for 18-24 $\mathrm{h}$. The metabolism process produced the color's changing even after the addition of reagent into the NIT, PAL and VP medium (Langlois et al., 1983).

The suspension from API STAPH from NIT, PAL and VP medium after addition of reagent showed the positive changing color (Fig. 3.) with all medium changed from red into yellow, and ADH and URE from yellow into pink. 


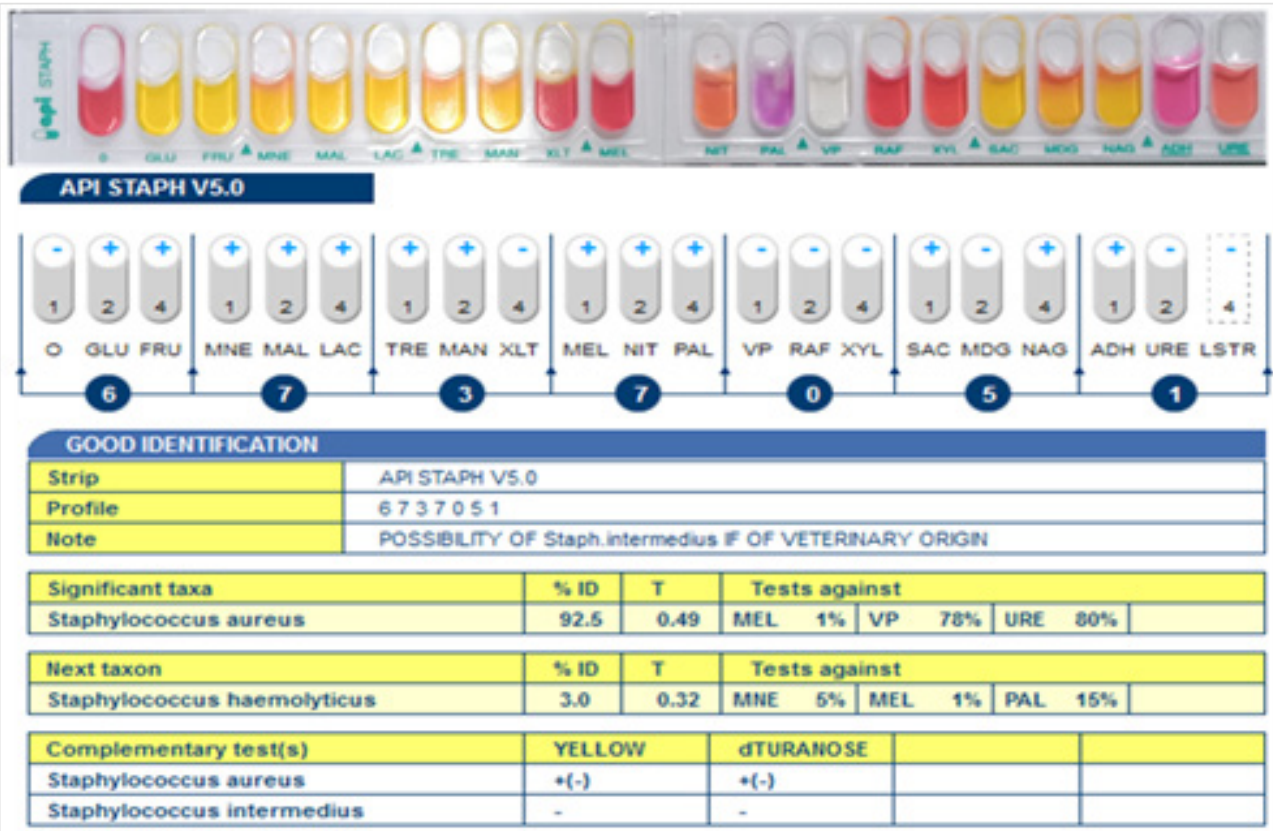

Figure 3. API STAPH confirmation analysis

\section{Discussion}

Suspected colony of Staphylococcus aureus in this research was able to appear as black color colony surrounded by clear zone when inoculated in BPA medium. This happened because there was lipolytic activity from $S$. aureus that reduced the tellurite into tellurium. The opaque zone caused by the proteolytic and lipolytic processes with the additional of egg yolk (Capita et al., 2001). The growth of $S$. aureus in BPA medium shows that this bacteria still presence in the milk product even though passing through the pasteurization process during the production. These suspected colony then regrowth in MSA medium. The growth of many species of bacteria, except Staphylococcus, was inhibited by $7.5 \%$ of sodium chloride. Mannitol is the carbohydrate source that can be fermented by $S$. aureus in MSA medium therefore, it produced yellow color colony in the end of the incubation time. The coagulate protein of negative species of Staphylococci and Micrococci did not fermented mannitol hence, growth as small red color colony (Pumipuntu et al., 2017).

Gram staining technique was done in this research to differentiate the group of positive and negative bacteria. Staphylococcus aureus is gram positive bacteria. Violet crystal colored cells will show the shape and color of $S$. aureus. This procedure produced the purple iodine area in the bacteria cytoplasm. Previous cells colored with violet crystal and iodine were then added by the mixture of acetone and alcohol to wash away the stain. The difference between gram-positive and gram-negative bacteria was its cell wall permeability (Elsa et al., 2010).

The isolate that has been analyzed for its carbohydrate fermentation was then analyze for its biofilm-forming indicator. Biofilm is a group of microbia cell that is irreversibly and related with the surface and close off matrix that mostly contains polysaccharide (Kim and Han, 2014). Ten isolates from different samples formed biofilm. Black and red colony in the surface of media showed the activity of $S$. aureus. Forming the biofilm is the survival mechanism of $S$. aureus. Black colony produced slime thus, indicated that biofilm is formed by Staphylococcus. Slime is produced because of the activity of fermentation enzyme (poly-N-acetylglucosamine; PNAG) that indicated by the appearance of black color in CRA medium. The use of high temperature in production process aimed to kill the opportunist bacteria. Not all of them were killed because of the biofilm formed by bacteria. The strain of bacteria that can 
produced slime or biofilm could increase its cell ability to survive from the process involved high temperature (Nermati et al., 2009).

Carbohydrate fermentation analysis was carried out using many kinds of sugar as its carbon source, there were xylose, maltose, sucrose, galactose, mannitol and VogesProskauer (VP) analysis. The purpose of this analysis was to convince that the suspected isolates were $S$. aureus. The changing color in the medium showed the forming of acid as the product from fermentation process by bacteria (Ajayi et al., 2017). The result of fermentation analysis showed that there were 6 suspected isolates of $S$. aureus. Those isolates the confirmed using API STAPH analysis. According to Table 1., isolate with codeS.B.4.3 was able to ferment xylose but not VP. Thus, it was predicted as Staphylococcus gallinarum. Suspected S. aureus isolates were able to ferment maltose, sucrose, galactose and mannitol. Other isolates were predicted as $S$. saprophyticus, $S$ epidermidis and $S$. lugunensis. These results need confirmation since it was still prediction. All of the isolates predicted for $S$. aureus were confirmed with API STAPH, while another isolate $(S$. saprophyticus, S. epidermidis and S. lugunensis) was taken one isolate per species as the representative.

The confirmation analysis using API STAPH was conducted for biochemistry analysis for Staphylococcus, Micrococcus and Kocuria. The result from Table 2. shows that the highest ID percentage was isolate S.K.1.1 from sweetened condensed milk sample. The ID percentage of $98 \%$ was confirmed as S. xylosus. Some suspected isolates from carbohydrate fermentation showed the positive identification as $S$. aureus. These results showed that $S$. aureus can still survive in dairy milk product even after passed through high temperature during pasteurization process. Isolate S.U.1.1 and S.U.3.4 confirmed as S. haemolyticus with ID percentage of $85.0 \%$ and S. xylosus with ID percentage of $98.7 \%$, respectively. The ability of predicted Staphylococcus to ferment sugar medium was different. Not all the predicted S. aureus in Table 1 . ferment all the sugar medium. It can be seen in Figure 3. that there was different reaction indicated by the changing color after incubated for 18-24 h. All medium was incubated in aerobic condition, except for arginine dihydrolase (ADH) and URE medium were incubated in anaerobic condition. Fermentation results showed that the medium color in well changed from red into yellow and for ADH and URE changed from yellow into pink. The result with $92.5 \%$ percentage of ID was identified as $S$. aureus with the rest ( $3 \%$ ID) was S. haemolyticus. Thus, it supported the different results after confirmation analysis conducted.

\section{Conclusion}

There were 8 isolates identified as $S$. aureus with the percentage ID up to $92 \%$ and were able to form biofilm. Another isolates identified as S. xylosus and S. haemolyticus, with the percentage ID of $98.7 \%$ and $85 \%$, respectively.

\section{References}

Adetutu, A.A., Oritsewehinmi, B., Ikhiwili, O.M., Moradeke, A.O., Odochi, A.S., \& Adeola,O.A. ( 2017). Studies on Staphylococcus aureus isolated from pimples. Pakistan. Journal of Biological Science, 20(7), 350-354.

Argudín, M.Á., Mendoza, M.C., \& Rodicio, M.R. (2010). Food poisoning and Staphylococcus aureus enterotoxins. Toxins, 2(7), 1751-1773. Doi:10.3390/ toxins 2071751

Bnyan, I. (2013). Detection of Adhesion Genes and Slim Production among Staphylococcus aureus and Staphylococcus epidermidis Isolated from Hemodialysis Patients. College of Medicine, University of Babylon. Hilla, Iraq

Brooks, G.F., Carroll, K.C., Butel, J.S., Morse, S.A., \& Mietzner, T.A. (2013). Mikrobiologi Kedokteran Ed.23, Translation of Jawetz, Melnick, and Adelberg's Medical Microbiology, $23^{\text {th }}$. McGraww-Hill, US

Casagrande, P. P., Stefanetti,V., Hyatt, D.R., Marenzoni,M.L., Capomaccio,S., Coletti, M., \& Passamonti, F. (2015). Phenotypic and genotypic characterization of canine 
pyoderma isolates of Staphylococcus pseudintermedius for biofilm formation. Journal of Veterinary Medical Science, 77(8), 945-951. doi:10.1292/jvms.150043

Capita, R., Allonso-Calleja, C., Moreno, B., \& Garcia-Fernandez, M.C. (2001). Occurrence of Listeria species in retail poultry meat and comparison of a cultural/immunoassay for their detection. The Journal of Food Microbiology, 39, 321-325

Dai, J., Wu, S.,Huang, J., Wu, Q., Zhang, F., Zhang, J., Wang, J., Ding, Y., Zhang, S., Yang $\mathrm{X} .$, Lei, T., Xue, L., and $\mathrm{Wu}, \mathrm{H}$. (2018). Prevalence and characterization of Staphylococcus aureus isolated from pasteurized milk in China. Front. Microbiol. 10,641. doi: 10.3389/ fmicb.2019.00641

Elsa, H.W., Maria, L.R., Tereza, C.R., Luciane, B.M., Lina, C.A., \& Vanerli B. (2010). Assesment of the risk of raw milk consumption related to Staphylococcal food poisoning. Accessed 27 March 2015

Jin, W., \& Yamada, K. (2016). Staphylococcal enterotoxins in processed dairy products. Food Hygiene and Toxicology in Ready-toEat Foods, 241-258. doi:10.1016/b978-012-801916-0.00014-5

Johler, S., Weder, D., Bridy, C., Huguenin, M.-C., Robert, L., Hummerjohann, J., \& Stephan, R. (2015). Outbreak of staphylococcal food poisoning among children and staff at a Swiss boarding school due to soft cheese made from raw milk. Journal of Dairy Science, 98(5), 2944-2948. doi:10.3168/jds.2014-9123

Kadariya, J., Smith, T, C., \& Thapaliya, D. (2014). Staphylococcus aureus and Staphylococcal Food-Borne Disease: An Ongoing Challenge in Public Health. BioMed Research International, 2014, 1- 9. doi: 10.1155/2014/827965

Kim, M \& Han, M. (2014). Characteristics of biofilm development in an operating rainwater storage tank. Environmental Earth Sciences, 72(5), 1633-1642. https:/ / doi.org/10.1007/s12665-014-3067-2

Kumar, A., Alam, A., Rani, M., Ehtesham, N. Z., \& Hasnain, S. E. (2017). Biofilms:
Survival and defense strategy for pathogens. International Journal of Medical Microbiology, 307(8), 481-489. https:/ / doi.org/10.1016/j.ijmm.2017.09.016

Langlois, B.E., Harmon, R.J., \& Akers, K. (1983). Identification of Staphylococcus species of bovine origin with the API Staph-Ident system. Journal of Clinical Microbiology, 18(5), 1212-1219.

Nemati, M., Hermans, K., Devriese, L. A., Maes, D., \& Haesebrouck, F. (2009). Screening of genes encoding adhesion factors and biofilm formation in Staphylococcus aureus isolates from poultry. Avian Pathology, 38(6), 513-517. https://doi. org/10.1080/03079450903349212

Olwal, C. O., Ang'Ienda, P. O., Onyango, D. M., \& Ochiel, D. O. (2018). Susceptibility patterns and the role of extracellular DNA in Staphylococcus epidermidis biofilm resistance to physico-chemical stress exposure. BMC Microbiology, 18(1), 1-13. https://doi.org/10.1186/ s12866-018-1183-y

Palilu, P. T \& Budiarso, T. Y. (2017). Isolation and identification of Staphylococcus sp. In powdered infant milk. AIP Conference Proceedings 1844, 020016 (2017); doi: 10.1063/1.4983427

Pumipuntu, N., Kulpeanprasit, S., Santajit, S., Tunyong, W., Kong-ngoen, T., Hinthong, W. , \& Indrawattana, N. (2017) Screening method for Staphylococcus aureus identification in subclinical bovine mastitis from dairy farms. Veterinary World, 10(7),721-726.

Qian, W., Shen, L., Li, X., Wang, T., Liu, M., Wang, W., \& Zeng, Q. (2019) Epidemiological Characteristics of Staphylococcus aureus in Raw Goat Milk in Shaanxi Province, China. Antibiotics, 8(3), 141. doi:10.3390/ antibiotics8030141

Rohinishree, Y \& Negi, P. S. (2011). Detection, Identification and Characterization of Staphylococci in Street Vend Foods. Food and Nutrition

Scallan, E., Hoekstra, R. M., Angulo, F. J., Robert, V. T., Marc-Alain, W., Sharon,L. R., Jeffrey, L.J., \& Patricia, M. G.(2011). Foodborne illness acquired 
in the United States - majorpathogens. Emerging Infectious Diseases. 17, 7-15. doi: 10.3201/eid1701.P11101.

Savage, E., Chothe, S., Lintner, V., Pierre, T., Matthews, T., Kariyawasam, S., \& Jayarao, B. (2017) Evaluation of Three Bacterial Identification Systems for Species Identification of Bacteria Isolated from Bovine Mastitis and Bulk Tank MilkSamples. Foodborne Pathogens and Disease, 14(3), 177-187. doi:10.1089/ fpd.2016.2222

Sutejo, S.V. H., Amarantini, C. \& Budiarso, T.Y. (2017) Molecular detection of Staphylococcus aureus resistant to temperature in milk and its products. AIP Conference Proceedings 1908, 050007 (2017) https://doi. org/10.1063/1.5012731

Vanderhaeghen, W., Piepers, S., Leroy, F., Van Coillie, E., Haesebrouck, F., \& De Vliegher, S. (2015). Identification, typing, ecology and epidemiology of coagulase negative Staphylococci associated with ruminants. The Veterinary Journal, 203(1), 44-51. doi:10.1016/j.tvjl.2014.11.001

Wu, S., Huang, J., Wu, Q., Zhang, F., Zhang, J., Lei, T., \& Xue, L. (2018). Prevalence and Characterization of Staphylococcus aureus Isolated from Retail Vegetables in China. Frontiers in Microbiology, 9. doi:10.3389/fmicb.2018.01263 